\title{
An experimental investigation on the effect of particle size into the flowability of fly ash
}

\author{
Lokesh Rohilla, Vivek Garg, S.S. Mallick*, Gautam Setia \\ Department of Mechanical Engineering, Thapar University, Patiala, Punjab-147004, India
}

\section{A R T I C L E I N F O}

\section{Article history:}

Received 23 May 2017

Received in revised form 12 December 2017

Accepted 9 February 2018

Available online 9 February 2018

\section{Keywords:}

Fly ash

Powder flow properties

Hoppers

Critical particle size

Wall friction

\begin{abstract}
A B S T R A C T
In this paper, physical properties and flow properties of fly ash collected from seven fields of Electro-Static precipitator (ESP) hoppers of a coal fired thermal power plant have been investigated by using Powder Flow Tester operating based on Jenike's methodology. It was experimentally observed that the fly ash from different ESP hoppers have different flow properties. Various powder flow properties, such as cohesion, unconfined yield strength, angle of internal friction and wall friction angle were found to have power law variation with median particle size. Critical particle size, which caused a change in the flow properties of fly ash from cohesive to easy flowing, was experimentally evaluated and validated. Hopper half angle and critical outlet opening trends were determined for different fly ash samples to achieve mass flow condition for discharge. Additionally, two power law models were also developed for estimating hopper half angle and critical outlet openings using powder flow properties.
\end{abstract}

(c) 2018 Published by Elsevier B.V.

\section{Introduction}

Fly ash is a fine powder, which is classified as Group A or Group B powder as per Geldart's classification diagram [1]. Fly ash is produced after the pulverized coal is combusted in the boiler. After the combustion, fly ash solidifies quickly, resulting in nearly $90 \%$ of amorphous glass content and rest is in crystalline form. Fly ash particles could be hollow from inside with a thin wall outside and in some cases, it has been reported that the hollow fly ash particle encapsulates smaller fly ash particles in them [2]. The fly ash is captured by the charged plates in the Electro-Static Precipitator (ESP) unit and further rapping action is used to dislodge fly ash particles from these plates. These dislodged fly ash particles fall into the ESP hoppers directly below the ESP charged plates. Generally, there are seven or more fields of ESP in a modern coal fired super thermal power station ESP hoppers underneath every field. ESP hopper acts as a temporary storage for ash evacuation and conveying systems. Any interruption in their discharge capabilities can affect the performance of the entire ash handling unit by reducing the ash evacuation rates. Improper design of storage vessels causes problems, such as arching, ratholing, flooding etc., which have the potential to cause work stoppages [3]. The critical dimensions of ESP hoppers, such as the outlet opening and hopper half angle must be confirmed to achieve mass flow hopper design. Mass flow hopper design ensures continuous discharge from all parts of the hopper at a steady rate. In case the storage vessel does not confirm to the mass flow hopper

\footnotetext{
* Corresponding author.

E-mail address: ssmallick@thapar.edu (S.S. Mallick).
}

design, then funnel flow pattern would exist in which there would be stagnant zones of bulk powders near the hopper wall. Various researchers have studied the flow properties of different powders ranging from nano-particles to food powders. Lee et al. [4] investigated black soybean powder of different particle size at constant moisture content. The flow behaviour was investigated by a Brookfield, Powder Flow Tester (PFT). The fine powders were located in the cohesive ranges during powder flowablity tests and there was a sharp increase in their bulk density with an increase of consolidation stress. Abdullah and Geldart [5] conducted experiments on FRF and FCC (flame retardant powders) and suggested bulk density as the measure of cohesiveness. Their experiments reconfirmed that cohesion in the samples decrease with an increase in particle size. Liu et al. [6] investigated the effects of the particle size on the flow behaviour of pulverized coal. An annular shear tester was used to measure the flow properties and a transparent Plexiglas hopper was used to determine the discharge behaviour of different particle sizes. The bulk density values got to a constant value after $100 \mu \mathrm{m}$ and the samples having size smaller than this size were called fine samples (remaining were classified as coarse sample). The results were in agreement with the findings of other researchers $[7,8]$. They also studied the effect of particle size on the relative flow rate of each sample from the Plexiglas hopper designed using Jenike methodology. They suggested that the samples having HR (Hausner ratio) less than 1.25 are not affected by the intermolecular forces. For powders having HR between 1.25 and 1.4 lie in ' $\mathrm{A}$ ' to ' $\mathrm{C}$ ' boundary (Geldart diagram) and their cohesiveness decrease with particle size. Bian et al. [9] measured the bulk flow properties of hard red winter (HRW) and soft white winter (SWW) wheat flours. The average particle size of 
the powders was $48.77 \mu \mathrm{m}$ and $48.20 \mu \mathrm{m}$, respectively. Compressibility indexes (CI), Hausner ratio (HR), angle of repose (AOR) of the powders were measured. AOR of the powders were nearly same $\left(40.90^{\circ}\right.$ and $\left.41.57^{\circ}\right)$, but there was a huge difference between the values of $\mathrm{Cl}$ ( 8.20 and 41.57). This showed the counter intuitive behaviour of powders under different conditions. Fitzpatrick et al. [10] measured the flow properties of 13 food powders. They showed that there was no strong relationship between the flow and physical properties. Ganeshan et al. [11] reviewed various factors influencing the flowablity of powders, such as moisture content, humidity, pressure, temperature and particle size. Iqbal et al. [12] investigated the effect of storage conditions, such as temperature, storage time, relative humidity on the wall yield locus and further showed its effect on the hopper design. The food powders under investigation were flour $(73 \mu \mathrm{m})$, tea powder ( 25 $\mu \mathrm{m})$ and whey permeate $(98 \mu \mathrm{m})$. The powders were stored for 7 days and there were significant changes in the flow properties of hygroscopic powders, while the wall yield locus of flour remained unchanged. Their study highlighted the role of measuring the flow properties of powders under different storage conditions before proposing a storage vessel design. Krantz et al. [13] investigated the flow properties of the two samples of fine powders with median particle size between 21 and $31 \mu \mathrm{m}$ under the different stress states. The tests performed ranged from angle of repose, avalanche angle to bed expansion ratio tests. They were of the opinion that the selection of characterization technique should be based on the application of the powder. They concluded that the flow behaviour of the powders depends on the stress state and no single technique can fully characterize the powder. They also advocated that if the powder is subjected to multiple handling processes, such as storage, transportation, fluidization, then multiple testing techniques should be used to predict the behaviour of the powder. Lu et al. [8] further extended their work by investigating the flow properties of pulverized coal and found the dominant forces causing gravity discharge at different particle sizes. Lumay et al. [14] measured the flow properties of the powders and the grains. Their study included experiments on silicon carbide, flour and rice. They advocated that granular material is a complex system in which transitions of the states take place. They defined three states of a powder; first is the static state followed by a quasi-static state and finally the dynamic state. The steady state of the powder can be represented by the heap of the powder having some angle of repose. They presented a classification of the powders on the basis of angle of repose. Quasi static state is a transition between steady and dynamic state, which can be represented by small movement of particles in the sample. The quantitative measure of the quasi-static state can be made by conducting Hausner ratio tests. They observed that the two powders may have similar values of HR, but their compaction dynamics could be entirely different. Ripp et al. [7] recently conducted a study on flow properties of tef flour and seeds and determined the optimum mass flow storage vessel by using Jenike methodology. Xanthakis et al. [15] performed a study on the flow properties of titan, alumina and silica based nanopowders by using the Powder Flow Tester (PFT). The nanopowders taken for the study were of both hydrophobic and hydrophilic nature and had the same particle size. The nanopowders were made hydrophobic or hydrophilic by a surface modification technique called hydrophobization. The nanopowder samples were of same material and particle size, but still their flowablities were found to be quite different. They found that hydrophobic nanopowder samples had less flow function curve slope as compared to the hydrophilic ones in every case.

Marrup et al. [16] developed a simple mono-axial shear tester to investigate into the flow properties of raw meal cement at 3 consolidation stresses of $0.94,1.87$ and $2.79 \mathrm{kPa}$ and temperature up to $850{ }^{\circ} \mathrm{C}$. The flowablity of the powders was expressed by the flow factor, which was found to be almost constant up to $550{ }^{\circ} \mathrm{C}$, but above this temperature, large deviations were found in the flowablity of powder. The flowablity of the powder was reduced above $550{ }^{\circ} \mathrm{C}$ due to Calcination and Belite formation. Jager et al. [17] used Jenike approach to design a large scale (3150 L) conical hopper to store pharmaceutical chemicals. Their test products were seven grades of micro crystalline cellulose (MCC). The major highlight of their research work was the selection of optimum outlet opening and minimum hopper half angle for different flowablity materials. Geldart et al. [18] studied the relation between angle of repose and flowablity of the powder. Three standard flowablity measuring equipment naming Johnson indicizer cohesion tester, warren Bradford spring cohesion tester, Jenike shear tester results were used to find the correlation between flowablity of the powder and the angle of repose (AOR). The AOR values got increased with the percentage of fine material in the mixture. Sindel and Zimmermann [19] studied the sphere-surface type contact between a lactose particles attached to a probe and lactose tablets used as substrate. They compared an average adhesion per particle in case of a shear cell, the tensile tester and an atomic force microscope (AFM). The shear cell gave the highest adhesion followed by the tensile tester. There was a huge difference between the observations from AFM and Jenike shear tester. The authors concluded that it is very difficult to approximate the flow properties of a sample using only the information of individual particle contact. These conclusions are contradictory to the conclusions made by Colbert et al. [20], who found a very good correlation between the adhesion values from AFM and cohesion values obtained using FT4 rheometer. Danjo et al. [21] studied the effect of particle shape on the flowablity of powder. They concluded that there is an increase in the flowablity of the bulk solids when there is an increase in the shape factor of the particles. They introduced the new concept of apparent adhesion, which they defined as the ratio of the inter-particle forces and the external forces. If the external forces are less compared to the inter-particle forces holding the particle above the void then the void fraction of the bulk solids will not increase appreciably until the external forces are large enough to force the particle into the void. Leturia et al. [22] compared the traditional and new testing methods used for characterization of the powders. The investigation was performed on seven powders ranging from nano particles to Group B powders. Traditional testing methods were classified in 3 categories: testing under aerated conditions, free surface conditions and packed bed conditions. Classification was based on the stress level involved in the tests. The authors were of the view that the flow properties of the powders cannot be indicated by only one index, but rather the results of several characterization methods should be combined to obtain the complete understanding of the behaviour of powders during storage and transportation. The state of compaction and bed voidage were cited as the main factors, which influenced the flowablity of powders. Johanson and Berletta [23] reported the flow properties of silica and FCC powders. The novelty in their research was that they conducted the flow property tests under aerated conditions by modifying the Schulze ring tester. The base of the shear cell was having an air chamber and the top lid was permeable to allow the air to come through the sample. It was observed that the unconfined yield strength of the sample got reduced as the pressure drop across the powder bed was increased. In both the cases of FCC and silica, the unconfined yield strength decreased with the aeration rate. The research on powder flow application is exhaustive [24], where the researchers have studied different powders in order to understand the missing link of the effect of particle properties on their bulk behaviour. Impetus has not been given on the flow properties of dry fly ash (especially, the influence of particle size on the flow properties) to the best of author's knowledge. Above literature review provided us the motivation to investigate into the flow properties of fly ash. Fly ash is formed after a complex combustion process involving various phenomenon including ammonia slip, ammonium bisulphate formation etc. Concerns regarding the emissions of $\mathrm{NO}_{\mathrm{x}}$ from the boilers have resulted in the use of $\mathrm{NO}_{\mathrm{x}}$ reduction technologies after combustion, such as Selective Catalytic Reduction (SCR) and Non-Selective Catalytic Reduction (NSCR). These technologies involve injection of $\mathrm{NH}_{3}$ in the mixture of flue gas, which produces nitrogen and water. Excess injected $\mathrm{NH}_{3}$ may pass the SCR system unreacted and this is known as ammonia 
slip. SCR systems are followed by air preheaters and finally the flue gas (laden with fly ash) enters the ESP assembly. There have been some observations regarding the plugging and corrosion due to ammonium bisulphate formation in the air pre-heater. Ammonium bisulphate is formed from ammonia, water vapours and $\mathrm{SO}_{3}$. Ammonium bisulphate is corrosive in nature and its formation is governed by the concentration of $\mathrm{NH}_{3}$ in the flue gases and the prevailing temperature. The temperature favourable to the formation of ammonium bisulphate is approximately 148 to $218{ }^{\circ} \mathrm{C}$ [25]. This makes air preheater more prone to the deposition as compared to the ESP hoppers, where the ash is at an approximate temperature of $80^{\circ} \mathrm{C}$. Therefore the formation of ammonium bisulphate due to the presence of unreacted ammonia is very small in the ESP hoppers region. Nearly 70 to $80 \%$ of unreacted ammonia is captured in the fly ash stored in ESP hoppers. The effect of chemical reactions will be manifested in the modification of wall friction coefficient, which can have an effect on hopper design. Fly ash is used in various applications, such as cement manufacturing, brick making etc. These applications require effective and reliable storage and handling of fly ash in the power plant end (i.e. the requirement of an effective dry powder handling system). The main objective of this paper is to experimentally determine the powder flow properties of seven samples of fly ash and to investigate into the effects of particle physical properties on the flow properties of fly ash and also to determine the critical dimensions of mass flow hopper for different grades of fly ash.

\section{Material and methods}

\subsection{Samples}

For this study, seven fly ash samples (from seven different consecutive ESP fields) were collected from seven consecutive ESP hoppers (of the same power plant unit). Each sample was preheated in a baking oven at $103{ }^{\circ} \mathrm{C}$ for $3 \mathrm{~h}$ to remove any moisture content. For the sake of simplicity, the nomenclature of each fly ash sample has been given as F1 to F7 representing the ESP hopper from which the samples were collected (fields 1 to 7 ). Table 1 shows the physical properties of the fly ash samples. Particle size distribution was found by laser diffraction method and has been reported in Table 1 as $d_{10}, d_{50}$ and $d_{90}$ representing $10 \%$, $50 \%$ and $90 \%$ of the sample having diameter lower than the corresponding values. Fig. 1 shows the Scanning Electron Microscopy (SEM) images of F1 to F7 samples produced by scanning the topography. SEM images were captured at the Sophisticated Analytical Instruments Laboratory of Thapar University, Patiala. The powders were placed on Aluminium stubs using double sided carbon tape and coated with a $5 \mathrm{~mm}$ layer of gold/palladium in JSM-5510 Scanning Electron Microscope (make JEOL Ltd.). The instrument was operated at an accelerating voltage of $15 \mathrm{kV}$.

\subsection{Powder Flow Tester}

Powder Flow Tester (PFT) at the Laboratory for Particle and Bulk Solid Technologies, Thapar University was used to measure the flow properties of the fly ash samples. It is an annular shear tester in which

Table 1

Physical properties of seven fields of fly ash samples.

\begin{tabular}{lllllll}
\hline Samples & $\begin{array}{l}\mathrm{d}_{10} \\
(\mu \mathrm{m})\end{array}$ & $\begin{array}{l}\mathrm{d}_{50} \\
(\mu \mathrm{m})\end{array}$ & $\begin{array}{l}\mathrm{d}_{90} \\
(\mu \mathrm{m})\end{array}$ & $\begin{array}{l}\rho_{\mathrm{b}} \\
\left(\mathrm{kg} / \mathrm{m}^{3}\right)\end{array}$ & $\begin{array}{l}\rho_{\mathrm{p}} \\
\left(\mathrm{kg} / \mathrm{m}^{3}\right)\end{array}$ & $\mathrm{HR}$ \\
\hline F1 & 42 & 139 & 316 & 794.9 & 2015 & 1.07 \\
F2 & 23 & 102 & 235 & 781.6 & 2014 & 1.15 \\
F3 & 23 & 97 & 213 & 729.7 & 2018 & 1.20 \\
F4 & 18 & 69 & 170 & 732.7 & 2025 & 1.36 \\
F5 & 14 & 53 & 141 & 798.7 & 2032 & 1.42 \\
F6 & 12 & 41 & 108 & 766.8 & 2030 & 1.25 \\
F7 & 6 & 21 & 63 & 670.2 & 2025 & 1.45
\end{tabular}

the sample is filled in an annular shear cell and the lid on the top provides the consolidation stress over the powder. The shear cell is rotated at a known angular velocity to produce shear in the sample at a given consolidation stress. There are two lids which are used to conduct flow function and wall friction tests in PFT. Flow function lid is used to measure the yield locus in the powder. The vanes are provided on flow function lid to completely hold the sample and to ensure that the shear takes place between the layers of powder only. Wall friction tests were conducted with standard wall friction lid made of 304 stainless steel having 2B surface finish. 2B surface finish has been specified in ASTM A480 standards and its surface is moderately reflective, cold rolled and pickled [26]. The equipment was calibrated with BCR-116 limestone powder before conducting the experiments [27]. BCR-116 is a standard powder recommended by the manufacturer to calibrate PFT. All the experiments were conducted at $45 \%$ RH (Relative Humidity) and $25{ }^{\circ} \mathrm{C}$ temperature. These were the laboratory conditions when the experiments were conducted. The equipment operates with accompanying Powder Flow Pro software, which analyses the raw data and provides yield locus, flow function curves, trends for wall friction angle and angle of internal friction for powders.

\section{Results and discussions}

\subsection{Physical properties of fly ash}

It can be observed from the SEM images that the fly ash particles are generally of spherical shaped with the sizes gradually decreasing from F1 to F7. Between the fly ash particles, some angular particles can be found, which are believed to be carbonaceous material. Fisher et al. [28] used light microscopy to classify fly ash into 11 categories on the basis of morphology. They provided a morphogenesis scheme to illustrate relationship between the particle opacity and its composition. The exposure of fly ash to the combustion chamber causes a change in their shape from vesicular to circular. Vesicular particles have limited exposure to the combustion chamber temperature gradients and therefore their shape remains similar to the pre-combustion particle forms. Spherical particle were mostly found to be transparent indicating complete melting of the silicate material. Kamiya et al. [29] took SEM images of fly ash at high temperature and found that its morphology remains stable up to $1073 \mathrm{~K}$. The temperature of fly ash in the ESP hopper is much lower (nearly $80^{\circ} \mathrm{C}$ ) at which the morphology of the powders remain stable. Specific surface area of fly ash is more in the later stages of ESP hoppers because of the presence of smaller spherical particles. More surface area implies more intermolecular forces between the particles and such samples have poor flow properties. Weight forces in F1 sample largely outweigh the magnitude of intermolecular forces between the particles. It can be inferred that there exists a particular particle size (or sample) after which intermolecular forces become larger than weight forces. A reduction in median particle size from sample F1 to F7 was observed corresponding to a decrease in bulk densities. The quenching rate of fly ash is very high in the later stages of ESP, which captures the finest fly ash. Higher quenching rate inhibits the formation of crystalline phase (such as $\alpha$-Quartz and Mullite etc.) in fly ash and large quantity of amorphous glass content is produced. Amorphous glass has lower bulk density as compared other mineralogical components [2]. This could be the reason of reduction of bulk density from F1 to F7 samples. Apart from this, the particles of fly ash may be hollow from inside with a thick wall outside. It has also been observed that the hollow fly ash particle may encapsulate finer particles in them [30]. Fisher et al. [30] provided a hypothesis that encapsulation phenomenon is the result of the bubbling of the fly ash particle which takes place in the combustion zone. A non-combustible particle is heated progressively as it passes through the combustion chamber, which results in a temperature gradient over its surface. Dehydration of certain minerals, such as calcium carbonate $\left(\mathrm{CaCO}_{3}\right)$ particle is the source of $\mathrm{CO}_{2}$ and $\mathrm{H}_{2} \mathrm{O}$ on the surface of the non-combustible particle. 


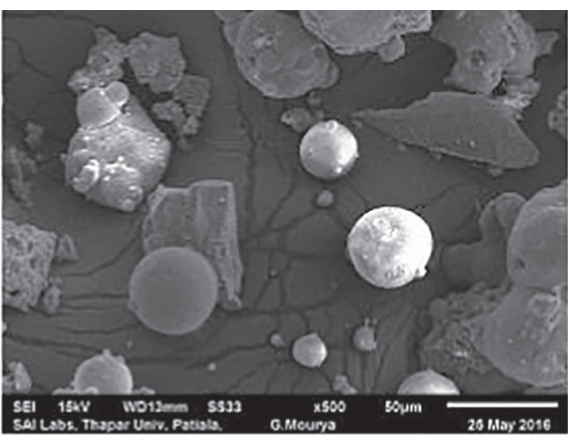

(a) F1

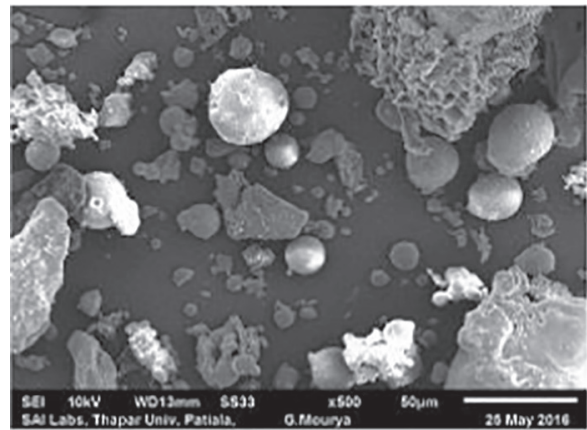

(c) F3

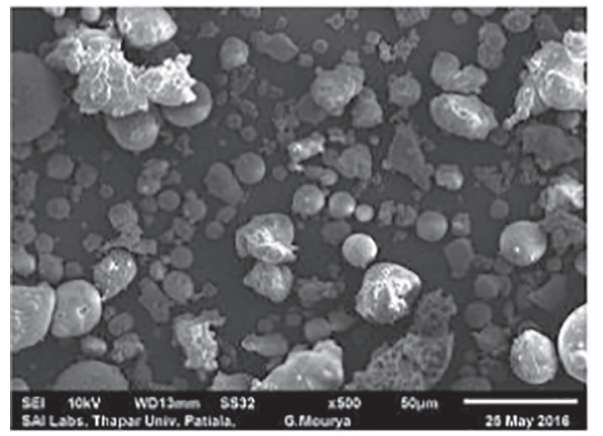

(e) F5

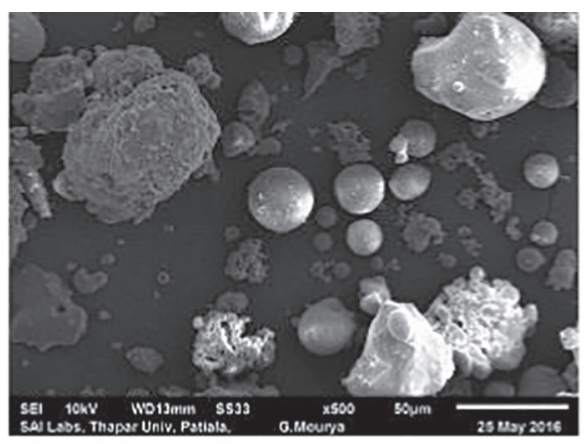

(b) F2

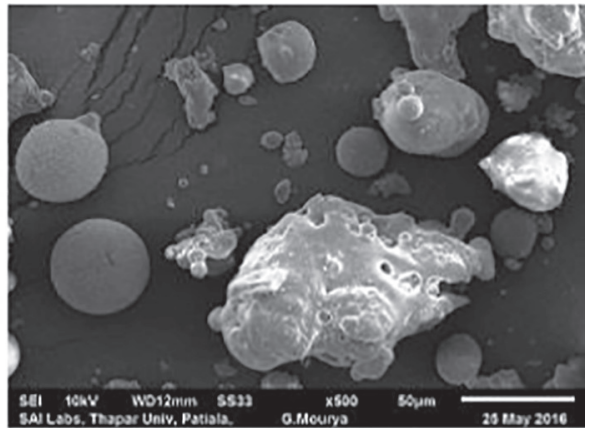

(d) F4

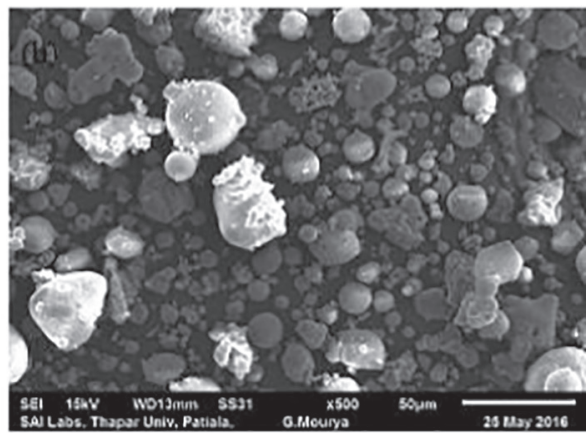

(f) F5

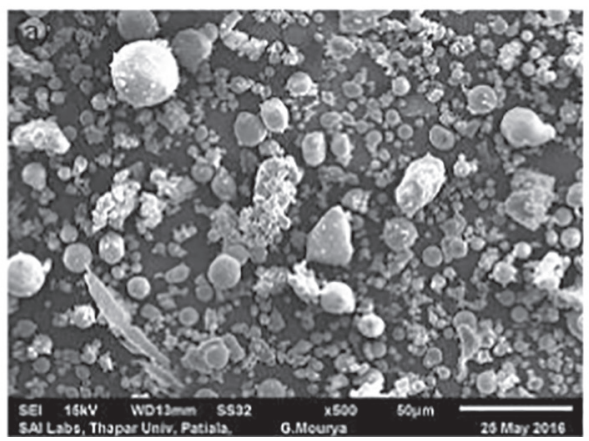

(g) F7

Fig. 1. SEM images of seven fly ash samples (F1 to F7).

The surface of the particle is surrounded by the plume of $\mathrm{CO}_{2}$ and $\mathrm{H}_{2} \mathrm{O}$ and its surface melts while the core of the particle either remains viscous or solid. The thermal conductivity of the encapsulating gas is less as compared to that of molten material on the surface of particle. Therefore the core continues to heat progressively and finally boils away with further formation of gas plume over its surface possibly resulting in the formation of solid microsphere inside the encapsulated fly ash particle. Furthermore, the spherical nature of the encapsulation suggests the dominance of pressure and surface tension as the governing forces in the phenomenon. Thus, combustion dynamics also affect the morphology of the fly ash produced. There was no trend observed in the particle density of fly ash with different samples for 
the same reason. Finer particle samples have good air retention capabilities, which further reduce their bulk density. Külaots et al. [31] studied the adsorption of ammonia over fly ash which is introduced in it for mitigation of $\mathrm{NO}_{\mathrm{x}}$ from coal fired boilers.

\subsection{Chemical properties of fly ash}

Chemical composition of fly ash of F1 to F7 sample was tested to determine the grade of fly ash. Energy Dispersive Spectroscopy (EDS) technique was used to identify the presence of different elements and their oxides. Fly ash mainly consisted of silicon and aluminium oxides. Some un-burnt carbon was also found in fly ash (observed by spectrograph). Table 2 reports the chemical composition of seven samples of fly ash. Total four spectrums were tested and the average results were used to evaluate the grade of fly ash. It was found that the tested fly ash samples were of F grade fly ash because the total silica and alumina content observed was more than $70 \%$.

\subsection{Yield locus and flow function curves}

The strength of the powder under a given consolidation stress is quantified by its yield locus. Yield locus has been extracted from PFT, which is an annular shear tester. Conventional Jenike shear tester has a limited translational movement, but annular shear tester can have infinite translational movement because of its annular geometry. Initially, the sample is loaded under a known pre-shear stress and is deformed continuously by the circular motion of the annular shear cell until the powder gives constant shear resistance. This process is also called homogenization of powder. Subsequently, the shear stress over the granular material is reduced to zero. The stress over the powder bed is reduced, but it still remains consolidated corresponding to initial preshear stress due to the reorientation of particles in the sample. After this new pre-stress (load) over the powder bed was introduced, which could be either greater or lower than the initial pre-shear stress under which the powder was homogenised. If the new pre-shear stress is lower than the initial pre-shear stress (for homogenization) and further shearing is performed, then the powder is said to be in an over-consolidated state of stress. On the other hand, if the new stress is higher than the initial homogenising pre-shear stress, then the powder is said to be in an under-consolidated state of stress. After initial preshearing, a lower load (pre-shear stress) is provided over the sample resulting in incipient flow (yielding) of powder at lower shear stress. These yielding points of powder at different lower pre-shear stresses are projected on shear stress $(\sigma)$ versus normal stress $(\tau)$ plot. These projections provide a single yield locus curve at a particular initial pre-shear stress used for homogenising the powder bed. Yield locus is a curve between normal consolidation load and shear stress. Five pre-shear stresses were considered in this study with three overconsolidation stress points. The granular material can deform infinitely until it yields under a given pre-shear stress. Yield locus for an ideal solid passes through the origin, but it would have some intercept on the ordinate for powders signifying some initial yield stress requirement to initiate flow in them at zero normal load. This intercept made by the yield locus at the ordinate is called cohesion (C) [3]. Cohesion of the granular material is measured at zero shear stress. Extrapolated

Table 2

Silicon and Aluminium oxide content in fly ash samples.

\begin{tabular}{llll}
\hline Sample & $\mathrm{SiO}_{2}$ content $(\%)$ & $\mathrm{Al}_{2} \mathrm{O}_{3}$ content $(\%)$ & Fly ash class \\
\hline $\mathrm{F} 1$ & 65.22 & 34.92 & $\mathrm{~F}$ \\
$\mathrm{~F} 2$ & 58.85 & 32.56 & $\mathrm{~F}$ \\
$\mathrm{~F} 3$ & 56.37 & 35.42 & $\mathrm{~F}$ \\
$\mathrm{~F} 4$ & 54.9 & 35.43 & $\mathrm{~F}$ \\
$\mathrm{~F} 5$ & 61.8 & 26.75 & $\mathrm{~F}$ \\
$\mathrm{~F} 6$ & 56.38 & 36.56 & $\mathrm{~F}$ \\
F7 & 52.23 & 30.47 & $\mathrm{~F}$
\end{tabular}

yield locus on abscissa represents tensile strength ( $T$ ) of the sample. Yield locus at any given pre-shear stress can be represented by Eq. (1).

$\tau=\sigma \tan \varphi+C$

where, $\varphi$ is the angle of internal friction representing the magnitude of friction between the layers of powder. Yield locus may have a curvilinear nature in which case Warren spring equation is used [11]. In this work, yield locus has been estimated by a linear Eq. (1) at five pre- shear stresses $\left(\sigma_{\text {pre }}\right), 0.317,0.610,1.207,2.414$ and $4.819 \mathrm{kPa}$ (and will be referred to as stresses 1 to 5 hereafter) and on each yield locus three over consolidation stress points were measured. Each yield locus provided major consolidation stress $\left(\sigma_{1}\right)$ on the powder element and unconfined yield strength $\left(\sigma_{\mathrm{c}}\right)$ of the powder. Unconfined yield strength signifies the strength of unsupported vertical column of powder consolidated with known pre-shear stress, which is analogous to the state of the powder element at the outlet of the hopper. Flow function curve is plotted between $\sigma_{1}$ and $\sigma_{\mathrm{c}}$. Fig. 2 shows the flow function curves for the seven fly ash samples. The flow function curve has been divided in four parts on the basis of Jenike's [32] flowability classification reported by Saw et al. [33]. The classification was based on the range of ratio $\sigma_{1} / \sigma_{\mathrm{c}}$ as follows: $\sigma_{1} / \sigma_{\mathrm{c}}<2$ for very cohesive powders, $2<\sigma_{1} / \sigma_{\mathrm{c}}<4$ for cohesive powders, $4<\sigma_{1} / \sigma_{\mathrm{c}}<10$ for the easy flowing powders and $\sigma_{1} / \sigma_{\mathrm{c}}>10$ for free flowing powders. Flow index (FI) which is the reciprocal of flow function curve slope $\left(\sigma_{1} / \sigma_{\mathrm{c}}\right)$ represents the relative flowability of the samples. It can be observed that the F1 sample remained easy flowing throughout the test stress range ( up to $10 \mathrm{kPa}$ ). Samples F2, F3 and F4 were in the cohesive region below stress 1 , but gradually shifted to easy flowing region. Sample F5 and F6 were in the cohesive region for stress 1 to stress 3 and finally shifted to easy flowing region for stress 4 to stress 5 . Table 3 reports flow index, slope of flow function curve and the flowability classification for the seven fly ash samples.

Sample F1 to F4 are of free-flowing nature and F6 and F7 are of cohesive nature with sample F5 ( $53 \mu$ m median particle size) being the transition sample between easy flowing and cohesive nature of fly ash. The compaction dynamics of F1 to F4 easy flowing samples and F5 to F7 cohesive samples can be represented by Eqs. (2) and (3), respectively.

$\rho_{b}=A \log _{n} \sigma+\rho_{o}$

$\rho_{b}=\rho_{o}+A \sigma^{4}+B \sigma^{3}+C \sigma^{2}$

where, $\rho_{o}$ is the loose pour bulk density, $\sigma$ is the major consolidation stress and $\mathrm{A}, \mathrm{B}, \mathrm{C}$ in the above equations are the constants dependent on the material. Flow index of samples F2 and F4 were same, but their compaction dynamics were entirely different. This observation shows

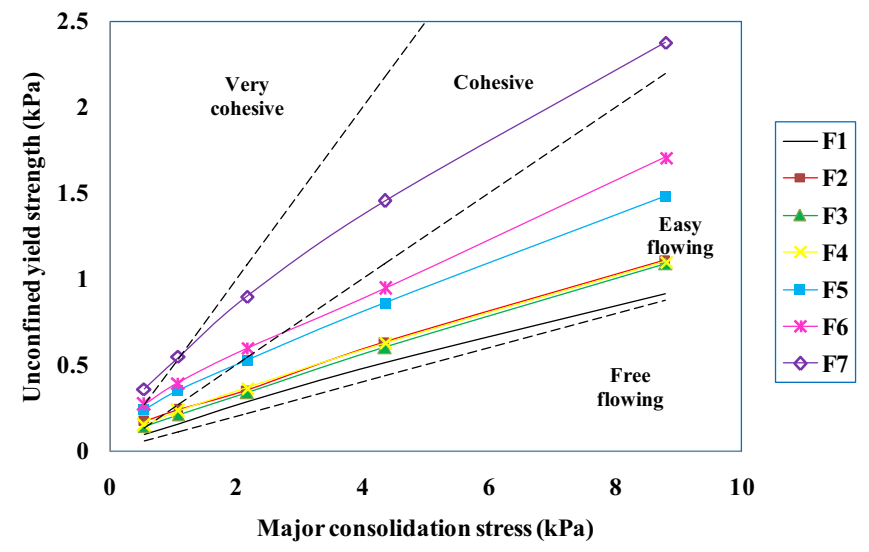

Fig. 2. Flow function curves for seven fly ash samples. 
Table 3

Flow index and slope of flow function curve at $\sigma_{\text {pre }}=1.2 \mathrm{kPa}$.

\begin{tabular}{|c|c|c|c|c|c|c|c|}
\hline Sample & F1 & F2 & F3 & F4 & F5 & F6 & F7 \\
\hline Flow index $\left(\mathrm{FI}=\sigma_{1} / \sigma_{\mathrm{c}}\right)$ & 7.69 & 5.88 & 6.25 & 5.88 & 4.16 & 3.70 & 2.56 \\
\hline Flow function curve slope & 0.10 & 0.12 & 0.16 & 0.12 & 0.15 & 0.17 & 0.24 \\
\hline Flowability classification & Easy flowing & Easy flowing & Easy flowing & Easy flowing & Easy flowing/cohesive & Cohesive & Cohesive \\
\hline
\end{tabular}

the significance of compaction dynamics for characterising different powders. It can also be observed from the compaction dynamics that sample F5 had the highest bulk density amongst all the samples. According to a study by Abdullah and Geldart [5], there is an optimum percentage of fine fractions in the powder, which provides the densest packing. This could be the reason for the highest bulk density of F5 sample during its compaction though its loose poured bulk density was sufficiently lower than F1 to F4 samples. Loose poured bulk density for easy flowing sample was higher than cohesive fly ash samples because the easy flowing samples pack well. The overall flowability of a sample depends on the magnitude of the intermolecular amongst the particles. Bond number (Bo) is the ratio of intermolecular forces of attraction $\left(\mathrm{F}_{\mathrm{a}}\right)$ and particle weight $(\mathrm{mg})$. It has been observed that the powders which pack well have good flowability characteristics because they have more weight force as compared to the magnitude of intermolecular forces [34]. Effective angle of internal friction $(\delta)$ is the ratio of major consolidation stress and minor consolidation stress over the powder element in the steady state flow. The variation of effective angle of internal friction with major consolidation stress is given in Fig. 3.

\subsection{Wall friction and bulk density tests}

Wall friction tests were conducted by using standard wall friction lid. The test procedure for wall yield locus is similar to flow function yield locus with the only difference that the slip is between wall and powder instead of the layers of powders. Wall yield locus was tested at a maximum stress of $4.817 \mathrm{kPa}$ by rotating wall friction lid 10 times with $0.006 \mathrm{~m}$ displacement. Effective angle of internal friction $\left(\varphi_{\mathrm{w}}\right)$ represents the friction between wall material and powder layer at a given normal stress. The variation of $\varphi_{w}$ with major consolidation stress is shown in Fig. 4. Bulk density tests were conducted simultaneously at 10 stress points with wall friction tests. Trends of bulk density values with major consolidation stresses are shown in Fig. 5.

\subsection{Critical dimensions of mass flow hopper}

Hopper half angle $(\theta)$ and outlet opening (D) are the critical parameters for mass flow pattern in a hopper irrespective of its structural design. Jenike [32] did pioneering work by deriving mathematical

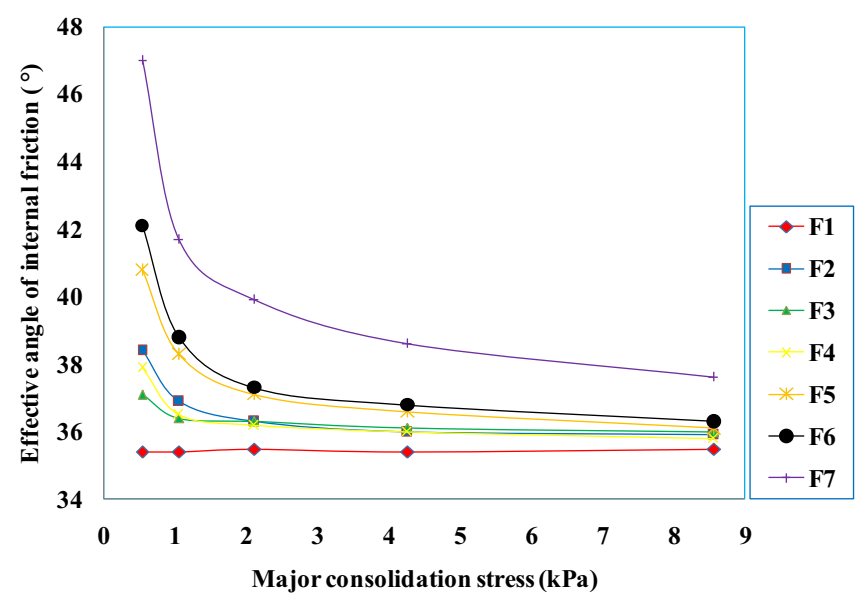

Fig. 3. Variation of effective angle of internal friction with major consolidation stress. relations between hopper critical dimensions and powder flow properties. Standard flow function tests and wall friction tests were conducted at five pre-shear stresses (represented as stresses 1 to 5). Hopper half angle and critical outlet opening were estimated using Eqs. (4) and (5).

$$
\begin{aligned}
& D=\frac{2 \times \sigma_{c} \times 1000}{\rho_{b} \times g} \\
& \theta=\left[90-\frac{1}{2} \cos ^{-1}\left(\frac{1-\sin \delta}{2 \sin \delta}\right)\right]-\frac{1}{2}\left[\varphi_{w}+\sin ^{-1}\left(\frac{\sin \varphi_{w}}{\sin \delta}\right)\right]
\end{aligned}
$$

Fig. 6 shows the variation of hopper half angle and outlet openings for seven fly ash samples measured at different pre-shear stresses (stresses 1 to 5). In Fig. 6, solid black line represents critical outlet opening, $\mathrm{D}=0.1 \mathrm{~m}$ and hopper half angle, $\theta=30^{\circ}$. These are the typical dimensions of ESP hopper.

for seven fly ash samples.

\subsection{Effect of particle size on flow properties of fly ash}

\subsubsection{Effect of particle size on cohesion}

The effects of particle size on cohesion for the seven fly ash samples at different pre-shear stresses have been shown in Fig. 7. It has been found that cohesion in fly ash decreases with an increase in median particle size. Fine particle samples (F5 to F7) are more cohesive because they have more surface area as compared to coarse particle samples (F1 to F4), which increases intermolecular forces of attraction [3]. Cohesion of the sample depends on the particle geometry, particle size and number of contact points. Compaction of the sample reduces intermolecular distance causing an increase in cohesion. Power law variation was observed for a decrease in cohesion with an increase in particle size, although the experimental data slightly deviated from power law at higher pre-shear stresses. The contact points between the particles of powder undergo deformation on increasing normal load over them. Flat contact points increase the surface area dependent forces, which increase the net intermolecular forces between the particles. Increased intermolecular forces cause an increase in bulk cohesion in the sample. Cohesion increases more quickly in fine samples as compared to coarse samples with increasing pre-shear stress. It can also be observed that cohesion is fairly constant for coarse samples (F1 to F4) at low pre-shear stresses, although, there were some deviations noticed at

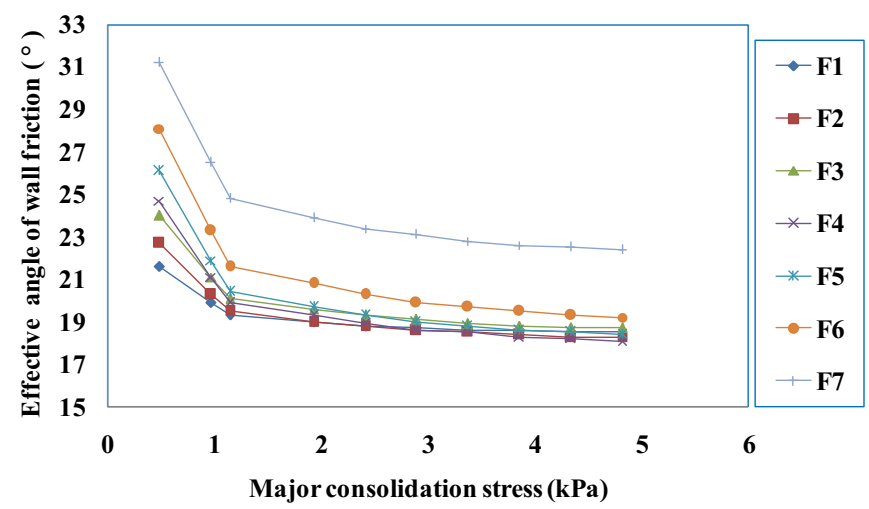

Fig. 4. Trends of effective angle of wall friction with major consolidation stress. 


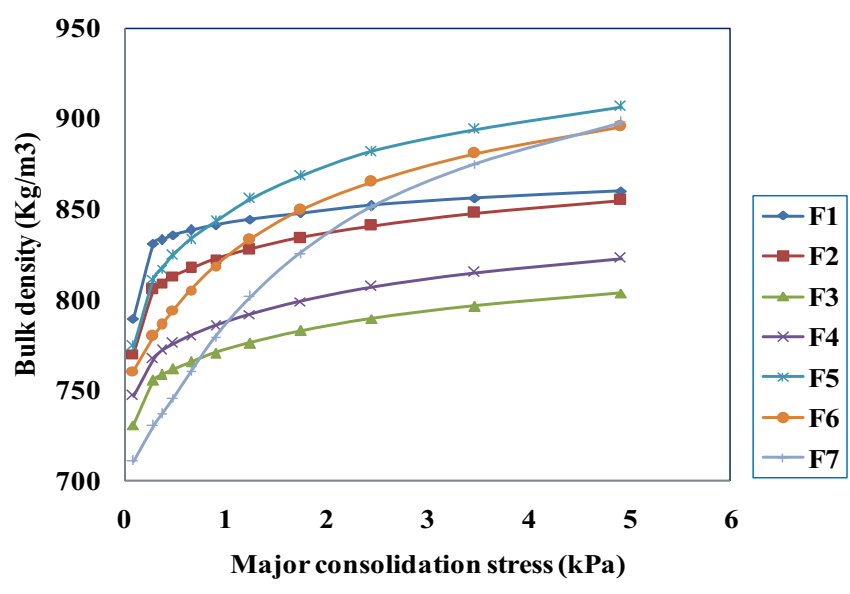

Fig. 5. Bulk density curves for seven fly ash samples.

higher pre-shear stress. At lower pre-shear stress range (stress 1 and 2), cohesion becomes independent of particle size after the transition sample (F5). This observation reconfirms the presence of critical particle size after which the weight force of the particle is balanced by net intermolecular forces of attraction (Bond number, Bo =1) [34]. Capece et al. [35] developed multi component granular bond number and correlated it with flow index of powder. They identified the boundary for powders at Bond number Bo $=1$ as the condition after which the particle weight force dominates particle intermolecular force, resulting in transition of their flow behaviour.

\subsubsection{Effect of particle size on angle of internal friction}

Angle of internal friction $(\delta)$ is the measure of friction between the layers of powders at a given pre-shear stress. It can be observed from Fig. 8 that $\delta$ for F1 sample is constant for all pre-shear stresses confirming its easy flowing behaviour. Flowability classification of F1 to F4 samples showed that all of them are easy flowing powders. Variation in the angle of internal friction with median particle size provided more insight about their flowability characteristics. A freeflowing material should have constant angle of internal friction throughout the stress range, which was only observed for the F1 sample. It was observed that power law fairly well represents $\left(R^{2}=0.85\right.$ to 0.95 ) the variation of $\delta$ with median particle size at different pre-shear stresses. Power law curves converged at a point for F1 sample (particle size $139 \mu \mathrm{m}$ ) after they were diverging for samples F2 to F7. The maximum divergence in power law curves was observed for F7 sample. The range of effective angle of internal friction $\left(\delta^{*}\right)$, which is the difference between highest $\left(\delta_{\max }\right)$ and lowest $\left(\delta_{\min }\right)$ value of $\delta$ observed for the sample is able to differentiate between free-flowing and cohesive samples. Table 4 shows the values of $\delta^{*}$ for seven fly ash samples.

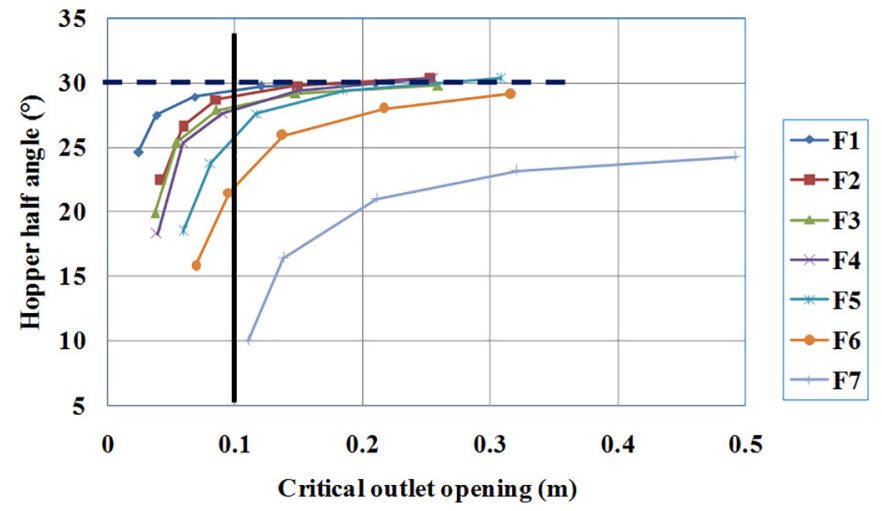

Fig. 6. Variation of hopper half angle with critical outlet opening.

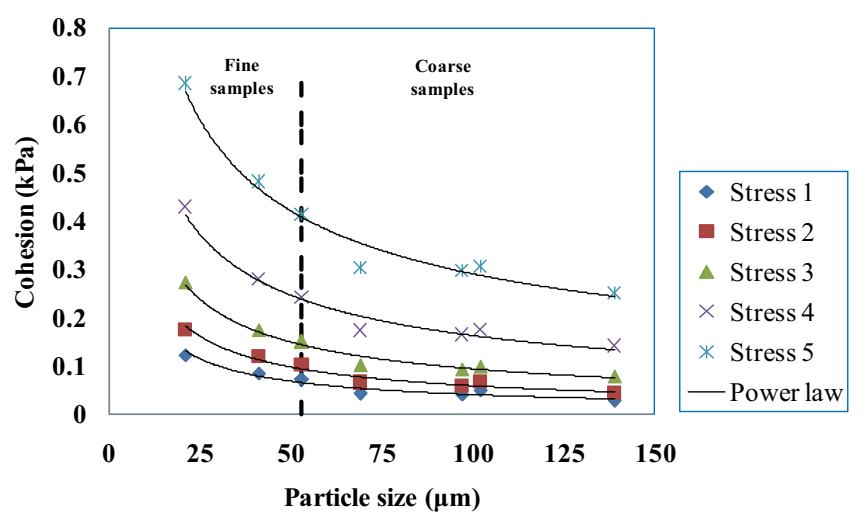

Fig. 7. Effect of median particle size on cohesion in seven fly ash samples at different pre-shear stresses.

Each sample had different values of $\delta^{*}$ representing the difference of flowability amongst easy flowing and cohesive samples. Fly ash having particle size more than $139 \mu \mathrm{m}$ will come under the category of freeflowing samples in absence of any moisture content as shown in Fig. 8.

\subsubsection{Effect of particle size on unconfined yield strength}

Fig. 9 shows the variation of unconfined yield strength with median particle size. It was observed that the trends follow power law, especially at lower pre-shear stresses. Fine samples had higher unconfined yield strength because of their capability to form stable structures. SEM images of F5 to F7 sample revealed presence of smaller sized spherical particles, which provided compact structure by filling all the voids when any normal stress is applied over these samples. On the other hand, coarse samples had fairly constant unconfined yield strength especially at lower pre-shear stresses. Transition particle size boundary has also been shown in Fig. 9 revealing the transition in unconfined yield strength of fly ash samples. Unconfined yield strength affects critical outlet opening of mass flow hopper (refer to Eq. (4)).

\subsubsection{Effect of particle size on wall friction angle}

The variation of wall friction angle $\left(\varphi_{\mathrm{w}}\right)$ with particle size has been reported in Fig. 10. Stresses 1 to 10 represent ten equally spaced normal stresses ranging from $0.482 \mathrm{kPa}$ to $4.817 \mathrm{kPa}$ in an increasing order. It was observed that all the fly ash samples followed nonlinear power law variation especially at low normal stress. It can be inferred from the experimental data that the change in magnitude of $\varphi_{w}$ keeps on diminishing with increasing normal stress over the sample. Reduction

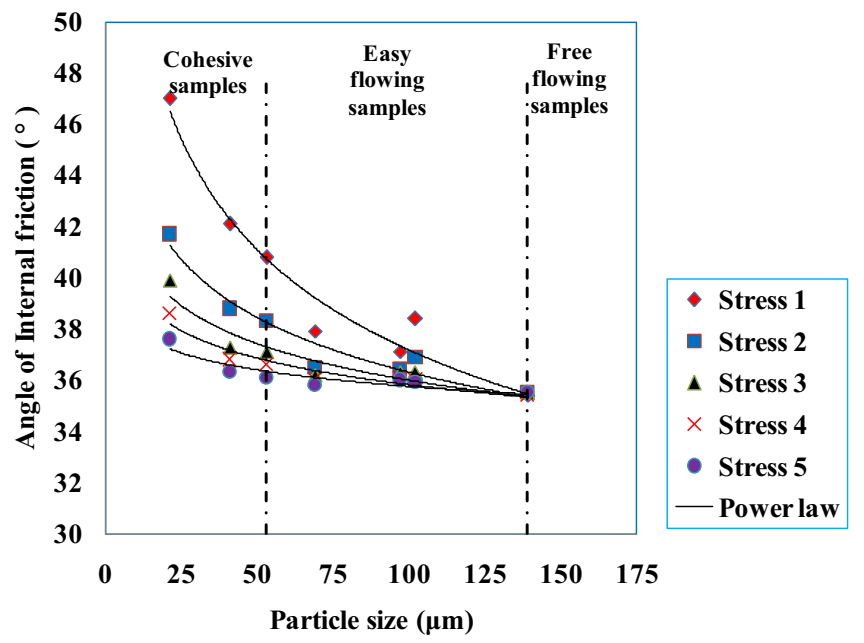

Fig. 8. Effect of particle size on Angle of internal friction. 
Table 4

Comparison of range of angle of internal friction with fly ash flowability.

\begin{tabular}{lll}
\hline Sample & Range of $\delta\left(\delta^{*}=\delta_{\max }-\delta_{\min }\right)$ & Flowability classification \\
\hline F1 & 0.1 & Easy flowing \\
F2 & 2.5 & Easy flowing \\
F3 & 1.1 & Easy flowing \\
F4 & 2.1 & Easy flowing \\
F5 & 4.7 & Easy flowing/cohesive \\
F6 & 5.8 & Cohesive \\
F7 & 9.4 & Cohesive \\
\hline
\end{tabular}

in $\varphi_{w}$ at higher consolidation stresses can be explained by smoothening of powder surface contacts. Smoothening of asperities with increasing consolidation load was recently reported by Chirone et al. [36] in his experimental data for radius of curvature of particle asperities. Fine sample particles got struck in the asperities of wall material resulting in higher $\varphi_{w}$ as compared to coarse samples. Average roughness for 2B surface finish stainless steel material ranges from $0.3 \mu \mathrm{m}$ to $0.5 \mu \mathrm{m}$.

\subsubsection{Correlation between particle physical properties and cohesion}

Saw et al. [37] recently presented an empirical model correlating powder cohesion and powder physical properties. The proposed model has been presented as Eq. (6). The model is power law based involving important parameters like median particle size, bulk density and particle density which have maximum effect on the flowability of the powder. The model additionally requires the ratio of unconfined yield strength, which makes shear testing of the sample mandatory for using the model.

$C=m\left(\frac{\rho_{b}}{\rho_{p} d}\right)^{a}\left(\frac{\sigma_{c}}{\sigma_{c \min }}\right)^{b}$

Eq. (6) was used for the shear testing data obtained for fly ash and the comparison between experimental and modelled results has been presented in Fig. 11. Coefficient of correlation between experimental and modelled cohesion data was 0.852 . The model fairly well represents cohesion in easy flowing samples and at low pre-shear stresses. The model was tested at all pre-shear stresses ranging from 0.318 to $4.856 \mathrm{kPa}$. It can be observed from Fig. 11 that the model gives large deviations for cohesive samples especially at higher pre-shear stresses.

\subsubsection{Effect of particle size on critical dimensions for hopper mass flow}

Different fields of an electrostatic precipitator accumulate fly ash of different particles size and flow properties. ESP hoppers are provided below the ESP to store fly ash for eight to ten hours. The critical dimensions of the mass flow hopper are its critical outlet opening and hopper

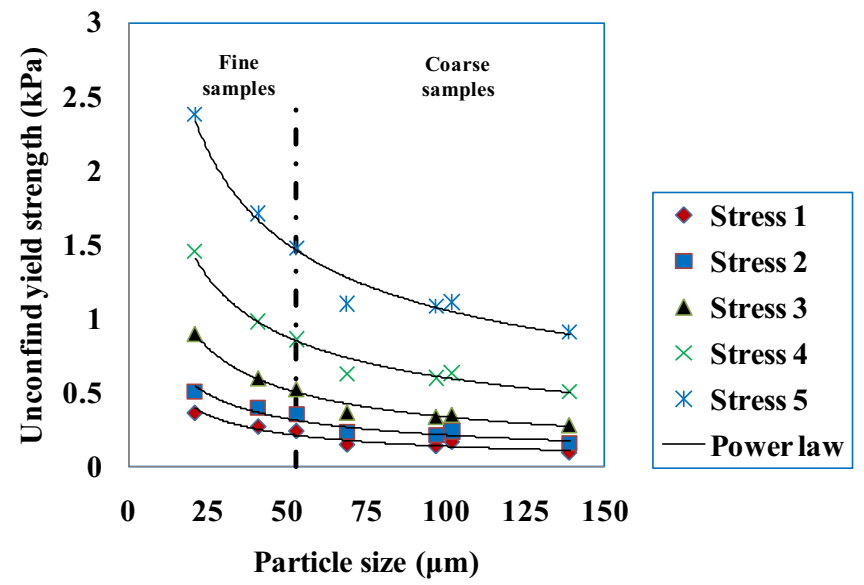

Fig. 9. Effect of particle size on unconfined yield strength.

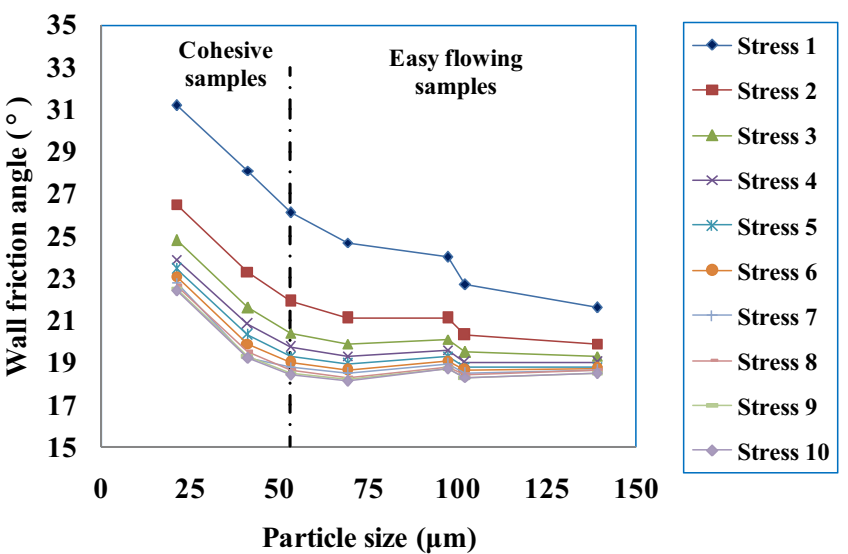

Fig. 10. Effect of particle size on wall friction angle at different normal stresses.

half angle with the vertical. More details about different configurations of mass flow hopper used in industries could be found elsewhere, see [3]. The design should consider the flowability of different fields of fly ash to ensure its continuous evacuation. Fly ash from different fields of ESP can be characterized by their different median particle diameter. Combustion of the pulverized coal in the combustion chamber is a complex process in itself. The fly ash particles could have different chemical composition and physical morphology on the basis of their exposure (temperature gradient) in the combustion chamber [28]. Pulverized coal particles are irregular in shape and combustion causes generation of vesicular and spherical shaped particles. Unburnt particles retain their vesicular shapes while completely burnt particles (fly ash) are spherical in shape. Thus, fly ash morphology depends upon the combustion process. Now, the ESP hoppers which are meant to store these polydispersed fly ash particles are commissioned at the beginning of the power plant. There is generally a broader idea about what type of coal will be burnt in the power station. However, during the operating condition, the coal could have different ash content, coal could be coming from different mines and the boiler could be running at part load condition. Therefore it is very difficult to assess what type of fly ash (in terms of physical and flow properties) will be formed during different operations of the boiler. Nonetheless, it is important for the plant operators to estimate the relationship between the physical parameter of fly ash, such as particle size and hopper dimensions. Therefore, an effort has been made here to provide the correlations for hopper critical dimensions (see Eqs. (7) and (8)). It has also been found during the study that all the ESP hoppers require different hopper half angle and outlet openings for achieving a reliable discharge. Fig. 12 shows the effect of median particle size of fly ash on the critical outlet opening for mass

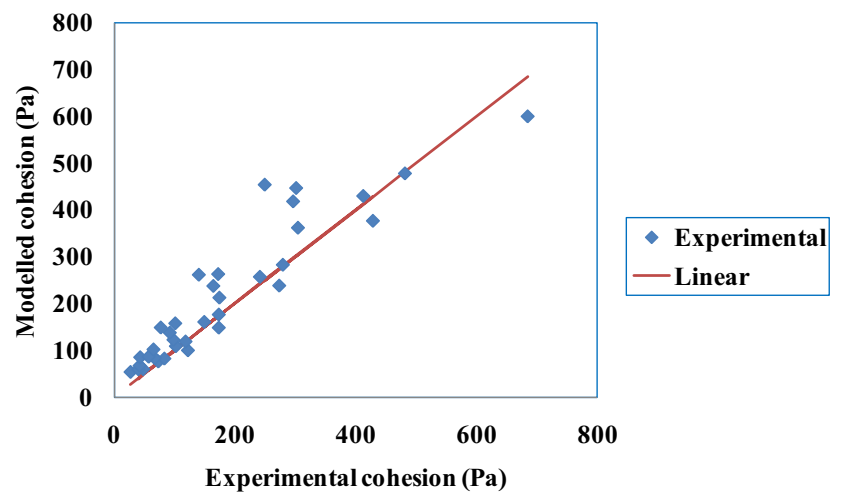

Fig. 11. Correlation between physical and flow properties of fly ash. 


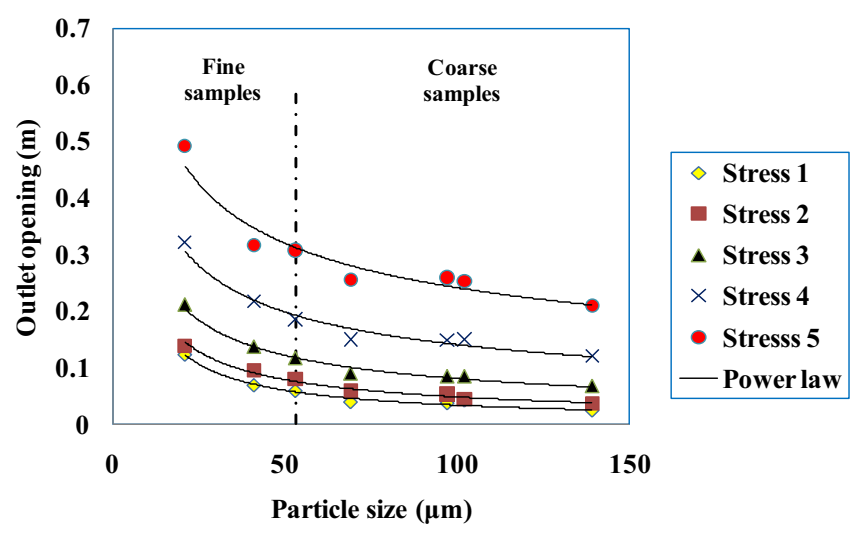

Fig. 12. Effect of particle size on hopper mass flow outlet opening.

flow hopper. It can be observed that the trends could be fairly well represented by power law variation, especially at relevant low preshear stresses.

The variations in hopper half angle with median particle size of seven fly ash samples have been shown in Fig. 13. Hopper half angle is dependent on both powder flow properties and wall friction characteristics. It was found that power law variation can only predict hopper half angle at low stresses (stresses 1 and 2 ) only with $\mathrm{R}^{2}$ values ranging from 0.92 to 0.93 . Hopper half angle becomes constant for coarse samples at higher pre-shear stresses, but it increased gradually for fine samples at all pre-shear stresses (refer to Fig. 13).

\subsection{Correlation for critical dimensions of mass flow hoppers}

In this study it was found that the variation of hopper critical dimensions for fly ash can be predicted better by power law based models. Fly ash is a poly dispersed powder and therefore its hopper critical dimensions do not vary linearly with flow index. Fig. 14 shows the variation of critical hopper outlet opening with flow index for seven fly ash samples at all pre-shear stresses. A good correlation was found between FI and critical outlet opening $\left(R^{2}=0.95\right.$ to 0.98$)$. Power law based relationships reliably predicted critical outlet opening for different fly ash samples.

It was observed that the hopper half angle can be predicted only at low pre-shear stress range (stresses 1 and 2 ) by power law equations by using median particle size. Eqs. (7) and (8) represented power law variation of hopper outlet opening and hopper half angle with flow index and particle size, respectively. These equations are accurate especially at low pre-shear stress levels, which are relevant for hopper design calculations because the magnitude of stress is very low at

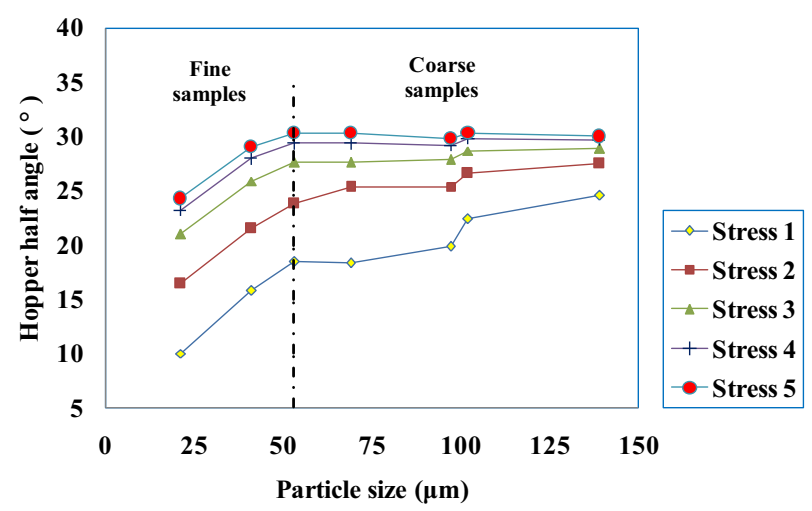

Fig. 13. Effect of particle size on hopper half angle.

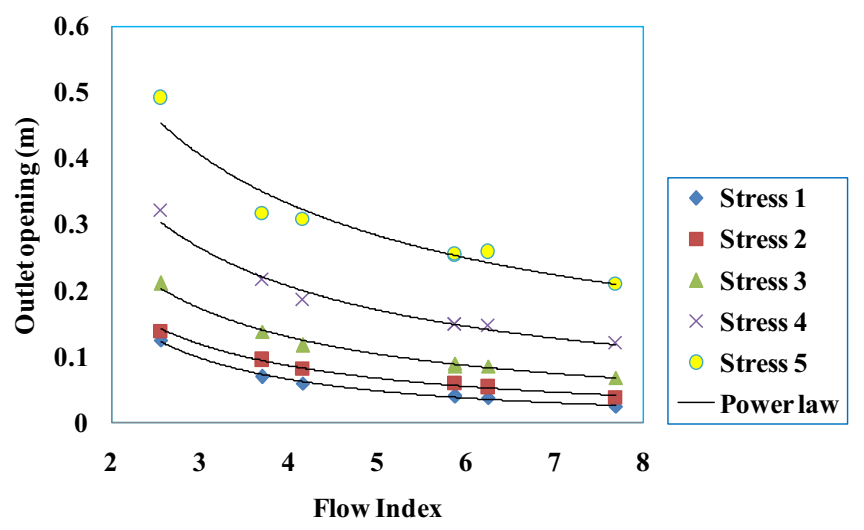

Fig. 14. Effect of flow index on outlet opening in a mass flow hopper.

the outlet of the hopper and flowability of fly ash at these stresses determine the performance of the hopper.

$D=a(F I)^{b}$

$\theta=x(d)^{y}$

Tables 5 and 6 show the constant parameters (a, b, x and y) used for modeling $\mathrm{D}$ and $\theta$ at different pre-shear stresses.

The present work provides detailed relationships between the different particle sizes to the corresponding flow function, wall friction etc. This has further provided relationships and models for hopper half-angle, opening size and cohesion with the variation of particle size of fly ash. Supported by such relationships/design guides, the designer of ESP hoppers will be able to better estimate the optimum combination of outlet opening and hopper half-angles. This is especially important for the finer fly ash (typically available from the 5th ESP field onwards), which being fine (and cohesive) often cause flow problems (arching/flow blockages) near the hopper outlet, requiring manual poking and/or the use of flow assistance accessories. Also, the designer would need to ensure that the ash discharge valves (located at the outlet of ESP hoppers) are able to provide sufficient flow dimensions, i.e. when fully open, the effective opening dimensions are not less than the critical hopper opening dimensions.

\section{Summary}

Flow properties, such as cohesion, angle of internal friction, unconfined yield strength, wall friction angle etc. were different for each fly ash sample (F type) collected from the different fields of ESP (from different ESP hoppers). Power law trend was observed in all the flow properties with variation in median particle size. SEM images and particle size analysis showed decrease in particle size from the first to seventh field ash. It was observed in this study that first to fourth field samples were easy flowing. This could be because the weight of a single particle was more than the net intermolecular forces of adhesion acting on it. Fifth to seventh field samples were having large specific surface area and more net intermolecular forces of attraction as compared to

Table 5

Correlation parameter for hopper critical outlet opening (D) for power law model.

\begin{tabular}{llll}
\hline Stress level & Parameter 'a' & Parameter 'b' & $\mathrm{R}^{2}$ value \\
\hline Stress 1 & 1.385 & 0.80 & 0.946 \\
Stress 2 & 1.201 & 0.69 & 0.980 \\
Stress 3 & 1.214 & -0.58 & 0.978 \\
Stress 4 & 1.388 & -0.49 & 0.959 \\
Stress 5 & 1.576 & -0.40 & 0.931 \\
\hline
\end{tabular}


Table 6

Correlation parameters for hopper half angle $(\theta)$ for power law model.

\begin{tabular}{llll}
\hline Stress level & Parameter ' $\mathrm{x}$ ' & Parameter 'y' & $\mathrm{R}^{2}$ value \\
\hline Stress 1 & 2.84 & 0.442 & 0.934 \\
Stress 2 & 7.803 & 0.285 & 0.919 \\
\hline
\end{tabular}

weight force of a single particle. The fifth field ash having $53 \mu \mathrm{m}$ median size served as the transition particle size between fine and coarse samples from the flow condition perspective. Additionally, the transition particle size was analysed by Jenike flowability classification and compaction dynamics of fly ash samples. Range of angle of internal friction $\left(\delta^{*}\right)$ served as a new parameter to differentiate between samples, which were classified under the same category by Jenike classification. Power law variation was observed for critical outlet opening for both coarse and fine samples. Hopper half angle was found to be dependent on both wall friction characteristics and powder flow properties. Flow index (FI) was used for the purpose of predicting outlet opening by using power law models at different pre-shear stresses. Power law based model provided satisfactory results for hopper half angle at low pre-shear stresses. This paper provided relationships between cohesion, hopper outlet dimensions and half-angles to particle size. The results have shown the requirement of additional outlet opening for finer fly ash (typically with the increase in the number of ESP fields). Future ESP hopper construction would need to ensure that minimum critical hopper opening dimensions are available to ensure the mass flow discharge of fly ash. If there are headroom or other practical restrictions, then flow assisting devices are to be provided (such as fluidizing air supply) to reduce the particle-particle-wall cohesive forces and thus ensuring higher rate of powder discharge.

\begin{tabular}{|c|c|}
\hline \multicolumn{2}{|c|}{ Nomenclature } \\
\hline C & Cohesion, $\mathrm{kPa}$ \\
\hline D & Minimum opening size, $\mathrm{mm}$ \\
\hline Bo & Bond number \\
\hline $\mathrm{F}_{\mathrm{a}}$ & Force of attraction between particles, $\mathrm{N}$ \\
\hline $\mathrm{mg}$ & Particle weight, $\mathrm{N}$ \\
\hline d & Particle size diameter, $\mu \mathrm{m}$ \\
\hline$\theta$ & Hopper half angle, $^{\circ}$ \\
\hline$\sigma$ & consolidation stress or normal stress, $\mathrm{kPa}$ \\
\hline$\sigma_{\text {pre }}$ & Pre-shear stress, kPa \\
\hline$\tau$ & Shear stress, kPa \\
\hline$\sigma_{1}$ & Major principle stress, kPa \\
\hline$\sigma_{\mathrm{c}}$ & Unconfined yield strength, $\mathrm{kPa}$ \\
\hline$\varphi$ & Angle of internal friction, ${ }^{\circ}$ \\
\hline$\rho_{\mathrm{b}}$ & Bulk density, $\mathrm{Kg} / \mathrm{m}^{3}$ \\
\hline$\rho_{\mathrm{p}}$ & Particle density, $\mathrm{Kg} / \mathrm{m}^{3}$ \\
\hline$\varphi_{\mathrm{w}}$ & Wall friction angle, ${ }^{\circ}$ \\
\hline$\sigma_{c, \min }$ & Minimum unconfined yield strength, kPa \\
\hline & Effective angle of internal friction, in degr \\
\hline
\end{tabular}

\section{Abbreviations}

FI Flow Index

$\mathrm{RH} \quad$ Relative Humidity

PFT Powder Flow Tester

SEM Scanning Electron Microscope

ESP Electrostatic precipitator

\section{References}

[1] P.W. Wypych, Pneumatic conveying of powders over long distances and at large capacities, Powder Technol. 104 (3) (1999) 278-286.

[2] S.H. Lee, E. Sakai, M. Daimon, W.K. Bang, Characterization of fly ash collected directly from electrostatic precipitator, Cem. Concr. Res. (1999) 1791-1797.

[3] D. Schulze, Powders and bulk solids, Behaviour, Characterization, Storage and Flow, Springer, 2008
[4] Y.J. Lee, W.B. Yoon, Flow behaviour and hopper design for black soybean powders by particle size, J. Food Eng. 144 (2015) 10-19.

[5] E.C. Abdullah, D. Geldart, The use of bulk density measurements as flowability indicators, Powder Technol. 102 (2) (1999) 151-165.

[6] Y. Liu, X. Guo, H. Lu, X. Gong, An investigation of the effect of particle size on the flow behaviour of pulverized coal, Proced. Eng. 102 (2015) 698-713.

[7] M. Ripp, Z.A. Debele, S. Ripperger, Determination of bulk flow properties of tef powder and seed and design of a silo, Part. Sci. Technol. 33 (2015) 494-502.

[8] H. Lu, X. Guo, Y. Liu, X. Gong, Effect of particle size on flow mode and flow characteristics of pulverised coal, Kona Powder Part. J. 32 (2015) 143-153.

[9] Q. Bian, S. Sittipod, A. Garg, R.K. Ambrose, Bulk flow properties of hard and soft wheat flours, J. Cereal Sci. 63 (2015) 88-94.

[10] J.J. Fitzpatrick, S.A. Barringer, T. Iqbal, Flow property measurement of food powders and sensitivity of Jenike's hopper design methodology to the measured values, J. Food Eng. 61 (3) (2004) 399-405.

[11] V. Ganesan, K.A. Rosentrater, K. Muthukumarappan, Flowability and handling characteristics of bulk solids and powders-a review with implications for DDGS, Biosyst. Eng. 101 (4) (2008) 425-435.

[12] T. Iqbal, J.J. Fitzpatrick, Effect of storage conditions on the wall friction characteristics of three food powders, J. Food Eng. 72 (3) (2006) 273-280.

[13] M. Krantz, H. Zhang, J. Zhu, Characterization of powder flow: static and dynamic testing, Powder Technol. 194 (3) (2009) 239-245.

[14] G. Lumay, F. Boschini, K. Traina, S. Bontempi, J.C. Remy, R. Cloots, N. Vandewalle, Measuring the flowing properties of powders and grains, Powder Technol. 224 (2012) 19-27.

[15] E. Xanthakis, J.R. van Ommen, L. Ahrné, Flowability characterization of nanopowders, Powder Technol. 286 (2015) 156-163.

[16] C. Maarup, K. Hjuler, K. Dam-Johansen, High temperature cement raw meal flowability, Powder Technol. 253 (2014) 686-690.

[17] P.D. Jager, T. Bramante, P.E. Luner, Assessment of pharmaceutical powder Flowability using shear cell-based methods and application of Jenike's methodology, J. Pharm. Sci. 104 (11) (2015) 3804-3813.

[18] D. Geldart, E.C. Abdullah, A. Verlinden, Characterisation of dry powders, Powder Technol. 190 (1) (2009) 70-74.

[19] U. Sindel, I. Zimmermann, Measurement of interaction forces between individual powder particles using an atomic force microscope, Powder Technol. 117 (3) (2001) 247-254.

[20] M.J. Colbert, M. Grandbois, N. Abatzoglou, Identification of inter-particular forces by atomic force microscopy and how they relate to powder rheological properties measured in shearing tests, Powder Technol. 284 (2015) 396-402.

[21] K. Danjo, K. Kinoshita, K.A. Kitagawa, K. Iida, H. Sunada, A. Otsuka, Effect of particle shape on the compaction and flow properties of powders, Chem. Pharm. Bull. 37 (11) (1989) 3070-3073.

[22] M. Leturia, M. Benali, S. Lagarde, I. Ronga, K. Saleh, Characterization of flow properties of cohesive powders: a comparative study of traditional and new testing methods, Powder Technol. 253 (2014) 406-423.

[23] K. Johanson, D. Barletta, The influence of air counter flow through powder material on the measurement, The 4th International Conference for Conveying and Handling of Particulates Solids, Budapest, Hungary May, 2003, pp. 4.39-4.44.

[24] S.S. Mallick, P.W. Wypych, Modeling solids friction for dense-phase pneumatic conveying of powders, Part. Sci. Technol. 27 (5) (2009) 444-455.

[25] G.F. Brendel, J.E. Bonetti, R.F. Rathbone, R.N. Frey, Investigation of Ammonia Adsorption on Fly Ash due to Installation of Selective Catalytic Reduction Systems. Technical report, 2000

[26] ASTM, A480/A480M-17 Standard Specification for General Requirements for Flat-Rolled Stainless and Heat-Resisting Steel Plate, Sheet, and Strip, ASTM International, West Conshohocken, PA, 2017https://doi.org/10.1520/A0480_ A0480M-17.

[27] R.J. Berry, M.S.A. Bradley, R.G. McGregor, Brookfield powder flow tester - results of round robin tests with CRM - 116 limestone powder, J. Proc. Mech. Eng. 229 (3) (2015) 215-230

[28] G.L. Fisher, B.A. Prentice, D. Silberman, J.M. Ondov, A.H. Biermann, R.C. Ragaini, A.R. McFarland, Physica and morphological studies of size-classified Cal fly ash, Environ. Sci. Technol. 12 (4) (1978) 447-451.

[29] H. Kamiya, H. Yamada, M. Tukada, M. Naito, Analysis of Ash Adhesion Behavior at High Temperature Condition by Using Computer Controlled FE-SEM with Heat Treatment unitIn United States http://www.osti.gov/scitech/servlets/purl/ 8358812002.

[30] G.L. Fisher, D.P. Chang, M. Brummer, Fly ash collected from electrostatic precipitators: microcrystalline structures and the mystery of the spheres, Science 192 (4239) (1976) 553-555.

[31] I. Külaots, Y.M. Gao, H.H. Robert, E.M. Suuberg, International ash utilization symposium, Center for Applied Energy Research, University of Kentucky, 2001 (Paper \# 59).

[32] A.W. Jenike, Storage and flow of solids, bulletin no. 123, Bulletin of the University of Utah, 53, , 1964 (26)

[33] H.Y. Saw, C.E. Davies, J.R. Jones, G. Brisson, A.H. Paterson, Cohesion of lactose powders at low consolidation stresses, Adv. Powder Technol. 24 (4) (2013) 796-800.

[34] A. Castellanos, The relationship between attractive interparticle forces and bulk behaviour in dry and uncharged fine powders, Adv. Phys. 54 (4) (2005) 263-376.

[35] M. Capece, R. Ho, J. Strong, P. Gao, Prediction of powder flow performance using a multi component granular bond number, Powder Technol. 286 (2015) 561-571.

[36] R. Chirone, D. Barletta, P. Lettieri, M. Poletto, Bulk flow properties of sieved samples of a ceramic powder at ambient and high temperature, Powder Technol. 288 (2016) 379-387.

[37] H.Y. Saw, C.E. Davies, A.H. Paterson, J.R. Jones, Correlation between powder flow properties measured by shear testing and Hausner ratio, Proced. Eng. 102 (2015) 218-225. 